\title{
SISTEM AUTENTIKASI HOSTPOT MENGGUNAKAN LDAP SERVER
}

\author{
Fianda Farabi Phasa, Joseph Dedy Irawan, Suryo Adi Wibowo \\ Program Studi Teknik Informatika S1, Fakultas Teknologi Industri \\ Institut Teknologi Nasional Malang, Jalan Raya Karanglo km 2 Malang, Indonesia \\ Adnaif.asahp17@gmail.com
}

\begin{abstract}
ABSTRAK
Jaman sekarang keamanan pada sistem jaringan komputer sudah sangat berkembang pesat, selain itu juga jaringan berbasis wireless sudah sering sekali kita temukan, jaringan tersebut juga harus dikombinasikan dengan keamanan yang baik. Pada saat ini pembuatan kemanan jaringan menggunakan Wireless sudah banyak ditemukan di sekitar kita tetapi dalam situasi dan kondisi pengamanan jaringan wireless yang banyak digunakan saat ini seringkali dapat dikatakan masih belum aman. Pasalnya, keamanan yang saat ini sering sekali kita temui yaitu seperti WPA, dan WPA2. hal ini masih dapat dikategorikan tidak aman dikarenakan keamanan yang banyak digunakan saat ini masih dikategorikan mudah dalam upaya pembobolan. Untuk itu diperlukan keamanan yang mumpuni dan mudah dalam proses manajemen user.

Maka dari itu penulis berencana mengembangkan keamanan jaringan menggunakan sistem authentikasi menggunakan LDAP server. Digunakan sistem authentikasi dinilai lebih aman, dikarenakan setiap pengguna akan dilakukan pengecekan identitas pada proses login ke dalam sebuah sistem jaringan. LDAP digunakan sebagai protocol direktori servis, dimana semua data user akan disimpan didalam LDAP sehingga akan lebih mempermudah dalam proses management user.. Pembuatan server menggunakan Ubuntu 14.04 (LDAP) dan Ubuntu 12.04 (Radius), dalam pembuatan server ini kedepannya akan lebih memudahkan untuk pengamanan jaringan pada user akun pengguna.

Karena itu, authentikasi menggunakan LDAP menjadi pilihan penulis untuk mengatasi masalah keamanan dan manajemen user pada jaringan komputer karena dinilai lebih mudah, aman dan efisien dalam hal keamanan dan pengelolaan user dalam sebuah jaringan.
\end{abstract}

Kata Kunci : Server, Ubuntu, LDAP, Radius, Hotspot.

\section{PENDAHULUAN}

Saat ini beragam cara yang dapat dilakukan untuk memanfaatkan layanan internet mulai dari cara yang konvensional sampai pada pemanfaatan teknologi komunikasi bergerak yang mempunyai layanan internet wireless untuk kebutuhan sehari-hari dalam mencari data dan informasi.Berawal dari masalah-masalah tersebut banyak metode pengamanan jaringan wireless dari sekala pengamnan sederhana seperti seperti wpa (wifi Protected Access), wpa2, wpa-psk dan sekala besar seperti metode sejenis yaitu sistem keamanan wireless perhotelan, perkantoran, dan perumahan yang menggunanakn captive portal.

Berbagai macam bentuk pengamanan jaringan wireless sudah ada dan banyak ditemui di sekitar kita akan teteapi bentuk pengamanan jaringan wirless ini harus disesuaikan dengan situasi dan kondisi lingkungan yang ada. Seperti halnya pada dilingkungan dengan memaanfatkan akun SIA (Sistem Informasi Akademik) yang bisa di integrasikan dengan pengamanan jaringan hotspot menggunakan LDAP

Manfaat yang didapat dalam sistem ini adalah kemudahan bagi setiap user yang hanya mempunyai satu akun terintegrasi untuk bisa mendapatkan fasilitas internet tanpa mengenyampingkan aspek keamanan yang ada.
Berdasarkan pemaparan di atas, sedikit diulas permasalahan tentang implementasi HOSTPOT dengan menggunakan LDAP Server. Oleh karena itu, untuk melakukan penelitian tentang Implementasi HOSTPOT Dengan Menggunakan LDAP (Lightweight Directory Access Protocol) Pada Jaringan Wireless

\section{TINJAUAN PUSTAKA}

\subsection{Penelitian Terdahulu}

Penggunaan Mikrotik Router Os berfungsi untuk penghubung antar dua atau lebih jaringan untuk meneruskan data dari satu jaringan ke jaringan lainnya, salah satunya adalah jaringan Hotspot. Hotspot sendiri merupakan wilayah terbatas yang dilayani access point wireless LAN standart 802.11 $\mathrm{a} / \mathrm{b} / \mathrm{g}$, dimana user dapat masuk ke dalam access point secara bebas dan mobile menggunakan perangkat notebook, laptop, dan sejenisnya. Diperlukan system autentikasi, user management dan monitoring jaringan hotspot ketika computer atau notebook mengakses hotspot akan login memasuki hotspot. Penggunaan Mikrotik Router dapat memudahkan ISP atau perusahaan kecil yang ingin berlangganan Internet guna untuk memanagement jaringan Wireless maupun Wired. Walaupun sudah banyak tersedia perangkat router mini sejenis NAT, dalam 
beberapa kondisi penggunaan router menggunakan Mikrotik merupakan solusinya. [1]

Semakin meningkatnya ukuran dan jumlah perangkat jaringan akan semakin kompleks masalah pada jaringan sehingga diperlukan adanya pengawasan secara terus-menerus untuk menjamin ketersediaan atau availability layanan. Simple Network Management Protocol adalah Protokol yang dapat digunakan untuk melakukan menagemen jaringan. Dengan menggunakan protokol ini kita bisa mendapatkan informasi tentang status dan keadaan dari suatu jaringan. Protokol ini menggunakan transpor UDP pada port 161 .[2]

Monitoring jaringan merupakan sebuah kegiatan yang bertujua nuntuk mengatur system jaringan yang berada pada wilayah atau area tertentu yang memanfaatkan topologi jaringan tertentu. Pemantauan secara real time dilakukan untuk memperoleh data mengenai kondisi jaringan, informasi akan disampaikan pada client apa masalah

yang menyebabkan jaringan mengalmi gangguan dan mengirimkan pesan melalu telegram tersebut. Pesan yang disampaikan yaitu berupa informasi updown pada suatu jaringan, pengaktifan koneksi jaringan dan lain sebagaina. penggunaan aplikasi telegram merupakan solusi yang tepat untuk digunakan oleh pengatur jaringan dalam memonitor bandwidth pada sebuah jaringan. [3]

WLAN (Wireless Local Area Network: lazim dikenal orang awam dengan 'hotspot' atau 'wi- fi') merupakan jaringan yang tidak tampak karena merupakan gelombang radio. Di udara, gelombang radio dapat 'bertabrakan' atau 'menyatu' dengan gelombang radio lainnya. Terutama bila frekuensinya terlalu berdekatan, atau hilang olehpower (daya) gelombang radio yang lebih besar. Tentunya jaringan yang kita buat dapat menjadi tidak efisien.[4]

Kegiatan monitoring bandwith tidak bisa dilakukan secara online melainkan harus meremote aplikasi monitoring bandwidth tersebut padahal tidak semua koneksi di semua tempat mengijinkan akses remote. Selain itu, report dari monitoring bandwidth tidak bisa dilihat secara langsung dan realtime. Network Management System sebagai pusat penyimpanan untuk pengumpulan dan analisa dari data manajemen jaringan. Hasil yang diperoleh sistem dapat memonitor Host, Bandwidth, Log User, Dll . [5]

\subsection{Jaringan Hostpot}

Hotspot (Wi-Fi) adalah salah satu bentuk pemanfaatan teknologi WirelessLAN, pertama kali digagas tahun 1993 oleh Brett Steward (Haryadi,2016). Captive Portal merupakan juga dikenal dalam istilah Hotspot. Captive Portal akan menerima semua trafik dari client dan akan memeriksa apakah client tersebut telah melakukan otorisasi atau belum untuk menggunakan sumber daya jaringan

\subsection{Mikrotik Router Board}

Merupakan router embedded produk dari mikrotik. Routerboard seperti sebuah pc mini yang terintegrasi karena dalam satu board tertanam prosesor, ram, rom, dan memori flash. Routerboard menggunakan os RouterOS yang berfungsi sebagai router jaringan, bandwidth management, proxy server, dhcp, dns server dan bisa juga berfungsi sebagai hotspot server

\subsection{Authentication}

Autentikasi merupakan proses validasi user saat masuk kedalam sistem. Pada saat memasuki sistem, password dari user dicek melalui proses yang mengecek langsung ke daftar yang diberikan hak untuk masuk kedalam sistem tersebut. Autorisasi ini di set up oleh administrator, webmaster atau pemilik situs. Untuk proses tersebut, masing-masing user akan dicek dari data yang diberikannya seperti userid dan password serta hal-hal lain yang tidak tertutup kemungkinan. Melakukan autentikasi terhadap sebuah objek adalah melakukan konfirmasi terhadap kebenarannya.

\subsection{LDAP}

LDAP (Light Weight Directory Access Protocol) adalah sebuah protokol yang mengatur mekanisme pengaksesan layanan direktori (Directory Service), yang dapat digunakan untuk mendeskripsikan banyak informasi seperti informasi tentang people, organizations, roles, services dan banyak entitas lainnya. LDAP menggunakan model client-server, dimana client mengirimkan identifier data kepada server menggunakan protokol TCP/IP dan server mencoba mencarinya pada DIT (Directory Information Tree) yang tersimpan di server.

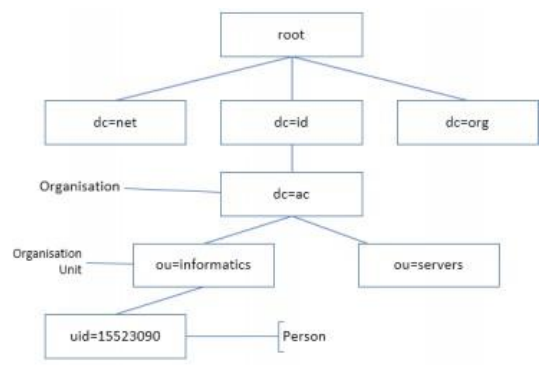

Gambar 1 Directory Information Tree

\subsection{Linux}

Linux adalah sistem operasi berbasis GNU/Linux yang bersifat Open Source dan memiliki banyak varian seperti Debian, Slackware, Open Suse, Archlinux, Redhat dan sebagainya. Walaupun sangat banyak varian GNU/Linux hanya menyediakan aplikasi yang sudah ditentukan yang mungkin kurang bermanfaat oleh pengguna sehingga hal ini mengakibatkan banyak pengguna yang melakukan remastering untuk memenuhi kebutuhannya. 


\subsection{Server}

Server, sesuai dengan namanya bisa diartikan sebagai pelayan pada suatu jaringan komputer. Server adalah komputer yang berfungsi untuk melayani, membatasi, dan mengontrol akses terhadap user-user dan sumber daya pada suatu jaringan komputer. Server merupakan suatu bagian terpenting dari sebuah jaringan. suatu jaringan komputer dengan banyak komputer memerlukan suatu server yang bertugas untuk menyediakan layanan yang dibutuhkan oleh user.

\subsection{Radius}

RADIUS adalah singkatan dari Remote Authentication Dial-in User Service yang berfungsi untuk menyediakan mekanisme keamanan dan manajemen user pada jaringan komputer. Radius diterapkan dalam jaringan dengan model clientserver. RADIUS merupakan suatu protokol yang dikembangkan untuk proses AAA (authentication, authorization, and accounting). Server Radius menyediakan mekanisme keamanan dengan menangani otentikasi dan otorisasi koneksi yang dilakukan user.

\section{METODE PENELITIAN}

\subsection{Topologi Jaringan}

Merupakan Desain atau Konsep yang digunakan peneliti yang berfungsi untuk membangun sistem yang di bangun.

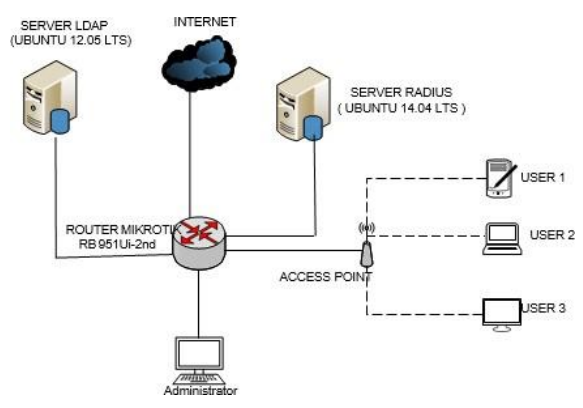

Gambar 2 Topologi Jaringan

Pada Gambar di atas merupakan topologi jaringan yang akan di gunakan dimana Internet sebagai uji coba untuk limitasi bandwidth setelah system sudah jadi. Kemudian di hubungkan dengan router mikrotik yang di gunakan untuk konfigurasi hotspot dan administrator sebagai controller. dari router mikrotik di hubungkan menggunakan access point sebagai pemancar sinyal, kemudian terdapat 3 user yang di hubungkan ke hotspot yang telah di konfigurasi . Berikut Penjelasan Ethernet pada Router mikrotik

1. Ethernet $1:$ Internet ( IP Address : 192.168.0.x )

2. Ethernet 2 : PC Server Radius (IP Address : 192.168.4.1)

3. Ethernet 3 :PC Server LDAP (IP Address : 192.168.5.1)

4. Wlan1 : Access Point (IP Address : 192.168.6.1)

5. Ethernet $4:$ Administrator (IP Address $: 192.168 .1 .2$ )

\subsection{Blok Diagram Sistem}

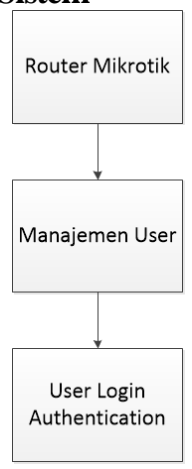

Gambar 3 Blok diagram sistem

Pada Diagram Blok di atas merupakan alur dari sistem yang akan di gunakan login admin sesuai dengan login admin pada mikrotik, mikrotik terhubung dengan internet. dari mikrotik melalui

internet dapat manajemen dan monitoring user layanan hotspot yang kemudian digunakan untuk user login. Berikut proses login user :

a. User terhubung dengan hotspot mikrotik.

b. User login hotspot dengan username dan password dan request ke mikrotik.

c. Mikrotik request login user ke server LDAP dan Radius , Radius menerima request login , kemudian melakukan otentikasi dan kemudian outorisasi.

\subsection{Flowchart Sistem}

Flowchart sistem ini menjelaskan proses berjalananya aplikasi seperti ditunjukkan pada Gambar 3. 




Gambar 4 Flowchart Sistem

Merupakan Flowchart dari alur jalan nya sistem , yang berawal dari login admin untuk membuka sistem . Admin login menggunakan username dan password, sistem akan melakukan pengecekan dengan database , kemudian admin dapat mengolah data user mengatur kecepatan bandwidth dan limitasi waktu yang di buat, dimana data user tersimpan pada server yang sudah terkoneksi dengan router mikrotik dengan batas user sebanyak maksimal 50 user, apabila terlebih dari 50 user maka resource dari mikrotik akan penuh dan router melambat .ketika user akan melakukan request maka mikrotik akan mengecek apakah user tersebut terdaftar pada server maka, apabila username dan password sudah terdaftar pada server, maka user akan mendapatkan response dengan bisa terkoneksi dengan jaringan. Apabila User Di Tolak maka

Username dan Password tidak terdaftar pada server sehingga user tidak dapat terkoneksi dengan jaringan. Untuk dapat terkoneksi dengan jaringan, maka user harus mendaftarkan pada administrator, kemudian administrator akan melakukan input user pada server radius, sehingga user akan dapat terkoneksi dengan jaringan.

\subsection{Struktur Menu}

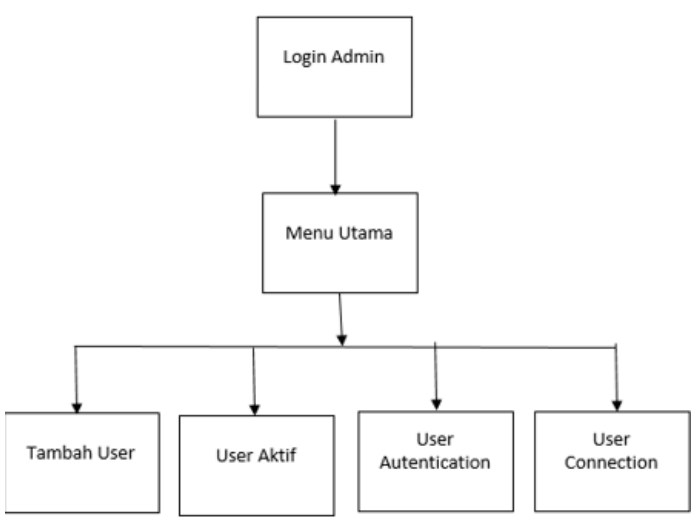

Gambar 5 Struktur Menu

Pada Gambar 5 Menunjukan Bahwa pada struktur website admin terdapat beberapa fitur atau menu yang mendukung administrator untuk mengolah data user, terdapat menu tambah user, user authentication, dan user Connection.

\section{HASIL DAN PEMBAHASAN \\ 4.1 Tampilan Login Admin}

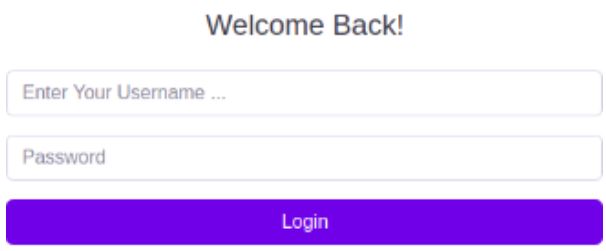

Gambar 6 Tampilan Login

Merupakan Implementasi dari halaman Login untuk administrator. Dimana Admin Memasukkan username dan password yang sebelumnya telah di buat pada database.

\subsection{Tampilan Halaman Monitoring A}
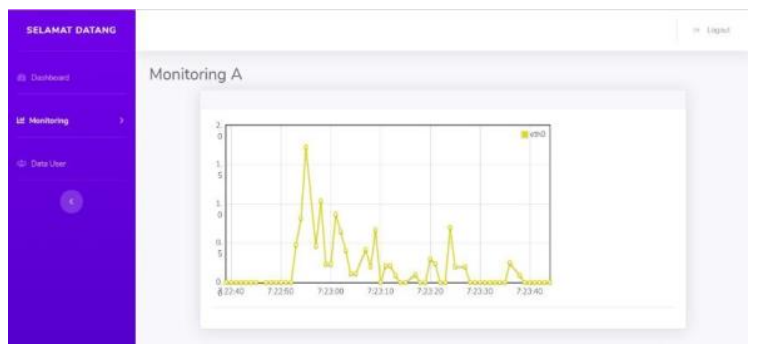


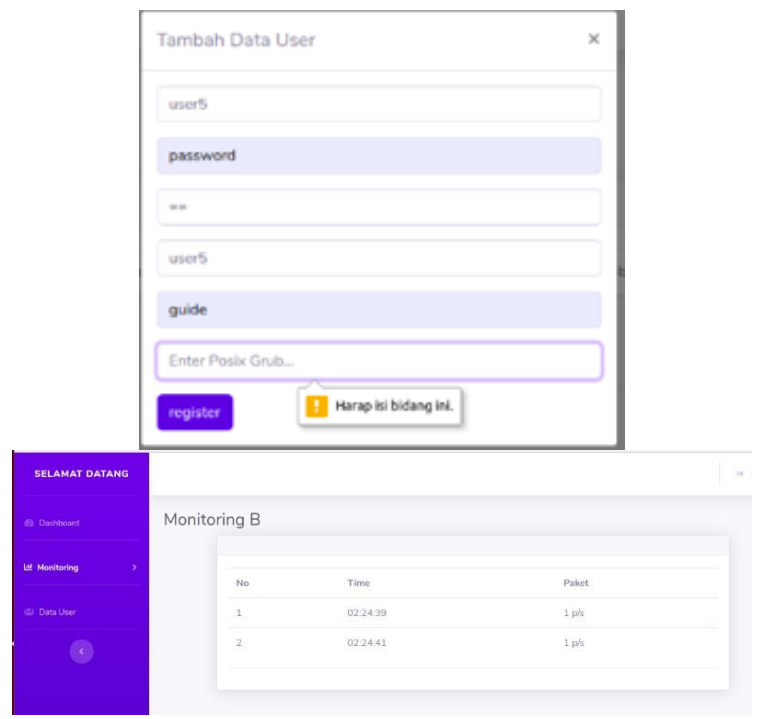

Gambar 8 Halaman Monitoring B

Merupakan implementasi dari halaman dashboard web based admin. Dimana Admin dapat memantau aktifitas Router Mikrotik, seperti resource rata-rata paket/detik menggunakan autentikasi ldap Versi Router dan Aktifitas User yang pernah atau sedang terkoneksi dengan jaringan hotspot.

\subsection{Tampilan Halaman User Aktif}
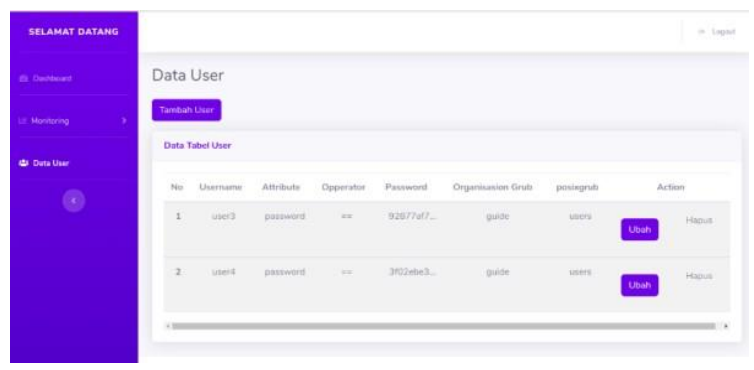

Gambar 9 Halaman User Aktif

Merupakan Implementasi dari halaman user yang sedang aktif mengakses jaringan, dimana admin dapat memantau user yang sedang aktif, terdapat username, ip address, organisasion grub dan posix grub.

\subsection{Tampilan Halaman Tambah User}
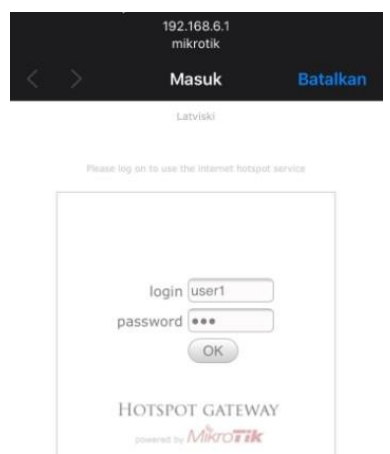

Gambar 11 Halaman Login
Merupakan pengujian Login User yang telah di tambah admin pada server radius, apabila sudah terdaftar maka User dapat mengakses jaringan tersebut

\subsection{Pengujian Server Ldap Pada Linux Ubuntu}

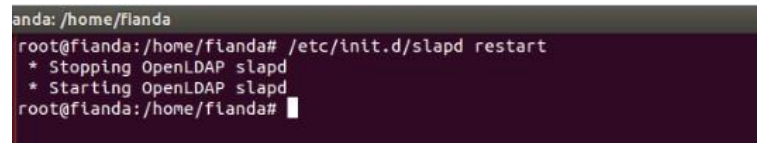

Gambar 12 integrasi pengujian sistem

Tahap pengujian ini dilakukan untuk mengetahui bagaimana cara menggunakan dan mengelola sebuah Server LDAP menggunakan OpenLDAP yang berfungsi sebaga backend database yang digunakan untuk penyimpanan akun login user, selain itu ditambahkan juga antarmuka phpldapadmin yaitu perangkat lunak yang berbasis web yang berfungsi untuk mengatur dan memudahkan pengelolaan akun di dalam LDAP server melalu web browser. Untuk memulai pengujian server ini kita jalankan server yangs sudah terinstal Ubuntu Server 14.04 dan Openldap

\subsection{Database phpldapadmin}

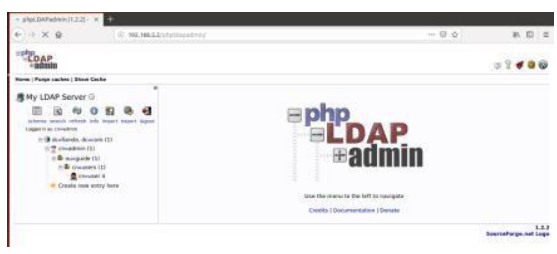

Gambar 13 pengujian database phpldapadmin

Setelah Openldap dijalankan pengelolaan databases bisa diakses langsung melalui perangkat lunak berbasis web yaitu phpldapadmin yang bisa diakses melalui web browser dengan mengetikan alamat url ip address seperti berikut 192.168.5.2/phpldapadmin.

\subsection{Pengujian Server Radius Pada Linux Ubuntu}

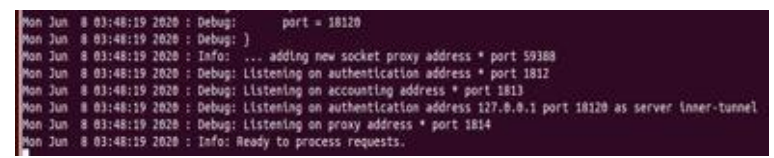

Gambar 14 Pengujian Freeradius -XXX

Pengujian Server radius, untuk melihat apakah terjadi error atau tidak, dengan perintah sudo freeradius $-\mathrm{XXX}$, apabila terdapat error maka akan terlihat report pada konfigurasi file yang terjadi kesalahan konfigurasi, apabila pengujian berhasil maka akan muncul report Ready To Process Request. 


\subsection{Konfigurasi Modul LDAP di Radius}

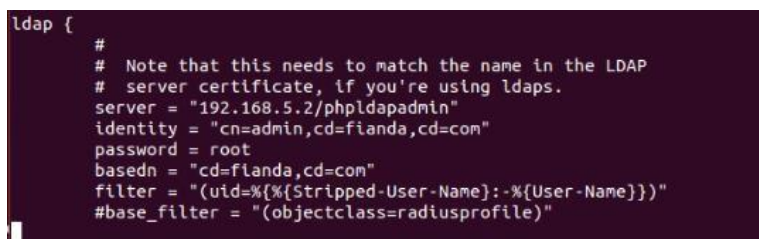

Gambar 15 Konfigurasi Modul LDAP di Radius

Konfigurasi Modul LDAP di Radius pada linux.Konfigurasi dilakukan agar database LDAP dapat terhubug ke Radius Server.Merupakan konfigurasi ip client radius, konfigurasi ini terdapat File Pada /etc/freeradius/modules/ldap ,konfigurasi ini berfungsi untuk menghubungkan database LDAP dengan radius.

Tabel 1 Pengujian Keamanan LDAP

\begin{tabular}{|c|c|c|c|}
\hline \multirow{2}{*}{ No. } & \multirow{2}{*}{ Item Uji } & \multicolumn{2}{|c|}{ Hasil Uji } \\
\cline { 3 - 4 } & & Berhasil & Gagal \\
\hline 1. & Pengujian Konektifitas & $\sqrt{ }$ & - \\
\hline 2. & Pengujian Organisasion Grub & $\sqrt{ }$ & - \\
\hline 3. & Pengujian Posix Grub & $\sqrt{ }$ & - \\
\hline 4. & Pengujian Account User & $\sqrt{ }$ & - \\
\hline 5. & Pengujian Transfer Data & $\sqrt{ }$ & - \\
\hline 6. & Pengujian Autentikasi user & $\sqrt{ }$ & - \\
\hline 7. & Pengujian Modul LDAP & $\sqrt{ }$ & - \\
\hline
\end{tabular}

Dari hasil pengujian diatas kita sudah mendapatkan hasil dari data uji masing-masing halaman keamanan LDAP, sebagaimana hasil tertera pada tabel 4.1.

Tabel 2 Pengujian User

\begin{tabular}{|c|c|c|c|c|}
\hline \multirow[b]{2}{*}{ No } & \multirow[b]{2}{*}{ Username } & \multirow[b]{2}{*}{ Password } & \multicolumn{2}{|c|}{ Hasil } \\
\hline & & & $\begin{array}{c}\text { Login } \\
\text { jaringan }\end{array}$ & $\begin{array}{c}\text { Akses } \\
\text { internet }\end{array}$ \\
\hline 1 & User1 & User1 & Berhasil & Berhasil \\
\hline 2 & User2 & User2 & Berhasil & Berhasil \\
\hline 3 & User3 & User3 & Berhasil & Berhasil \\
\hline 4 & User4 & User4 & Berhasil & Berhasil \\
\hline 5 & User5 & User5 & Berhasil & Berhasil \\
\hline 6 & User6 & User6 & Berhasil & Berhasil \\
\hline 7 & User7 & User7 & Berhasil & Berhasil \\
\hline
\end{tabular}

Pada Tabel 4.2 Pengujian dari sistem authentication dan authorize user, pada pengujian ini menggunakan 7 user, dari 7 user sistem web yang telah di bangun dapat berjalan dengan baik, dimana user ketika login username dan password yang telah di buat sesuai dengan sistem, sehingga terjadi proses authorization yang dimana user dapat mengakses jaringan hotspot tersebut misal dengan membuka jaringan internet .
Tabel 3 Tabel Pengujian monitoring sistem

\begin{tabular}{|c|c|c|c|c|}
\hline \multirow{2}{*}{ No } & \multirow{2}{*}{ Username } & \multicolumn{2}{|c|}{ Monitoring } & \multirow{2}{*}{ Hasil } \\
\hline & & IP Address & MAC Address & \\
\hline 1 & User1 & 192.168 .6 .3 & 20:5E:F7:EC:E9:94 & Berhasil \\
\hline 2 & User2 & 192.168 .6 .4 & 74:DF:BF:60:FA:53 & Berhasil \\
\hline 3 & User3 & 192.168 .6 .5 & 70:8B:CD:71:E9:70 & Berhasil \\
\hline 4 & User4 & 192.168 .6 .6 & CC:2D:83:A4:0D:7F & Berhasil \\
\hline 5 & User5 & 192.168 .6 .7 & 08:7F:98:D1:4D:A5 & Berhasil \\
\hline 6 & User6 & 192.168 .6 .8 & CC:2D:83:BA:2A:62 & Berhasil \\
\hline 7 & User7 & 192.168 .6 .9 & 20:5E:F7:EC:E9:94 & Berhasil \\
\hline
\end{tabular}

Merupakan Tabel Pengujian Monitoring Keseluruhan dari fungsional sistem, dari 7 user yang terkoneksi dengan jaringan hotspot, 7 user tersebut dapat tercatat pada sistem web mulai dari tercatat pada fitur user aktif ketika user terkoneksi dengan jaringan hotspot, User Authentication dimana user dapat login pada jaringan hotspot yang sebelumnya telah terdaftar pada server, dan User Log Connection User tercatat aktivitas Log IP address, Mac Address, dan waktu akses user.

Tabel 4 Tabel Perbandingan Sistem

\begin{tabular}{|c|l|c|c|c|}
\hline \multirow{2}{*}{ No } & \multicolumn{2}{|c|}{ Pengujian } & \multicolumn{2}{|c|}{ Hasil } \\
\cline { 3 - 5 } & & $\begin{array}{r}\text { Sistem Bawaan } \\
\text { Router (Winbox) }\end{array}$ & Server LDAP & Server Radius \\
\hline 1. & Create User baru & Mendukung & Mendukung & Mendukung \\
\hline 2. & $\begin{array}{l}\text { Manajemen Masa Aktif } \\
\text { User }\end{array}$ & Mendukung & Mendukung & Mendukung \\
\hline 3. & $\begin{array}{l}\text { Monitoring rata rata } \\
\text { kecepatan paket/detik }\end{array}$ & Mendukung & $\begin{array}{l}\text { Belum } \\
\text { Mendukung }\end{array}$ & $\begin{array}{l}\text { Belum } \\
\text { Mendukung }\end{array}$ \\
\hline 4. & $\begin{array}{l}\text { Monitoring rata-rata } \\
\text { keceptan autentikasi } \\
\text { LDAP }\end{array}$ & Mendukung & $\begin{array}{l}\text { Belum } \\
\text { Mendukung }\end{array}$ & $\begin{array}{l}\text { Belum } \\
\text { Mendukung }\end{array}$ \\
\hline 5. & $\begin{array}{l}\text { Monitoring Database } \\
\text { phpldapadmin }\end{array}$ & Mendukung & Mendukung & $\begin{array}{l}\text { Belum } \\
\text { Mendukung }\end{array}$ \\
\hline 6. & $\begin{array}{l}\text { Pengujian server LDAP } \\
\text { Ke Server Radius }\end{array}$ & Mendukung & Mendukung & Mendukung \\
\hline 7. & $\begin{array}{l}\text { Pengujian Server Radius } \\
\text { Ke Mikrotik }\end{array}$ & Mendukung & Mendukung & Mendukung \\
\hline
\end{tabular}

Pada Tabel 4.3 Merupakan tabel pengujian perbandingan antara sistem bawaan router (winbox), LDAP Server, Radius Server dengan sistem manajemen user berbasis web yang telah dibangun. Terdapat beberapa perbedaan antara winbox dengan sistem yang telah dibangun, pada winbox belum Mendukung monitoring awal dan akhir akses user mulai mengakses jaringan hotspot, tetapi pada sistem yang dibangun Belum Mendukung monitoring awal dan akhir akses user mulai mengakses jaringan hotspot. 
Tabel 5 Tabel Pengujian Server LDAP

\begin{tabular}{|c|l|c|}
\hline \multirow{2}{*}{ No } & \multicolumn{1}{|c|}{ Pengujian } & Hasil \\
\cline { 3 - 3 } & & Sistem yang bangun \\
\hline 1. & Create User baru & Mendukung \\
\hline 2. & Manajemen Masa Aktif User & Mendukung \\
\hline 3. & Monitoring User & Mendukung \\
\hline 4. & Create Organisasion Grub & Mendukung \\
\hline 5. & Create Posix Grub & Mendukung \\
\hline 6. & $\begin{array}{l}\text { Monitoring Database } \\
\text { phpldapadmin }\end{array}$ & Mendukung \\
\hline
\end{tabular}

Pada Tabel 4.4 Merupakan tabel pengujian fungsional Server Ldap untuk memantau log database user yang terdapat di phpldapadmin seperti Create User Baru, Manajemen masa aktif user , Monitoring user, Organisasion Grub dan Posix Grub.

Tabel 6 Tabel Pengujian Server Radius

\begin{tabular}{|c|l|c|}
\hline \multirow{2}{*}{ No } & \multicolumn{1}{|c|}{ Pengujian } & Hasil \\
\cline { 3 - 3 } & & Sistem yang dibangun \\
\hline 1. & Create User baru & Mendukung \\
\hline 2. & Manajemen Masa Aktif User & Mendukung \\
\hline 3. & Pengujian Modul LDAP & Mendukung \\
\hline
\end{tabular}

Pada Tabel 4.5 Merupakan tabel pengujian fungsional Server Radius Untuk memantau Aktifitas User dan integrasi ke modul ldap server

Tabel 7 Tabel Pengujian Fungsional

\begin{tabular}{|c|c|c|c|}
\hline \multirow{2}{*}{ No. } & \multirow{2}{*}{ Item Uji } & \multicolumn{2}{|c|}{ Hasil Uji } \\
\cline { 3 - 4 } & & $\sqrt{ }$ & - \\
\hline 1. & Halama Login & $\sqrt{ }$ & - \\
\hline 2. & Halaman User Aktif & $\sqrt{ }$ & - \\
\hline 3. & Halaman Tambah Data dan Edit & $\sqrt{ }$ & - \\
\hline 4. & Halaman Monitoring A & $\sqrt{ }$ & - \\
\hline 5. & Halaman Monitoring B & $\sqrt{ }$ & - \\
\hline 6. & Button Ubah & $\sqrt{ }$ & - \\
\hline 7. & Button Habus & $\sqrt{ }$ & - \\
\hline 8. & Button Tambah Data & $\sqrt{ }$ & - \\
\hline 9. & Button Update & $\sqrt{ }$ & - \\
\hline 10. & Button Logout & & \\
\hline 11. & Validasi Setiap Inputan & & \\
\hline
\end{tabular}

Dari hasil pengujian diatas kita sudah mendapatkan hasil dari data uji masing-masing halaman monitoring dan tombol button nya, sebagaimana hasil tertera pada tabel 4.6.

\section{KESIMPULAN DAN SARAN}

\subsection{Kesimpulan}

Berdasarkan Hasil dari Rancang Bangun Sistem autentikasi Hostpot menggunakan LDAP Server yang telah dilakukan maka didapat beberapa kesimpulan sebagai berikut:
1. Pengujian Server Radius dengan sistem operasi Linux Ubuntu 14.04 dapat berjalan.

2. Pengujian Server LDAP dengan sistem operasi Linux Ubuntu 12.04 dapat berjalan.

3. Rancang bangun Sistem autentikasi hotspot menggunakan LDAP dan RADIUS berhasil dibangun pada jaringan internet.

4. Pembuatan user akun pada LDAP telah berhasil dengan menggunakan antarmuka phpldapadmin yang diakses melalui web browser

5. Setiap server saling terintegrasi dan terkoneksi dengan jaringan internet, Server RADIUS sudah bisa melakukan akses ke database LDAP server menggunak Radtest.

6. Berdasarkan hasil pengujian keamanan jaringan yang terintegrasi dengan Server LDAP dan Server Radius, bahwa informasi berupa accoun user meliputi username dan password tidak dapat diketahui dengan mudah karena sudah terenskripsi dengan baik.

7. Hasil dari untuk mendapatkan user dan password yang digunakan untuk login hotspot dan ke server yang terintegrasi dengan Radius menggunakan LDAP dapat berjalan.

\subsection{Saran}

Berdasarkan peneltian yang telah dilakukan maka penulis dapat memberikan saran untuk pengembangan dan perbaikan kedepannya karena penelitian ini masih terdapat banyak kekurangan, sehingga perlu ada perbaikan dan penambahan sebagai berikut:

1. Sistem memiliki fitur untuk memutuskan koneksi user hotspot.

2. Penelitian lanjutan untuk menenamkan sistem yang sudah ada dengan menambahkan fitur fitur yang berada di database phpldapadmin untuk diimplementasikan.

3. Sistem memiliki fitur keamanan bagi jaringan hotspot dan server .

4. Penelitian lanjutan untuk adanya pengelolaan akun user olen admistrator jaringan.

5. Melakukan perawatan jaringan hotspot secara berkala untuk menjaga kinerja jaringan.

\section{DAFTAR PUSTAKA}

[1] Kusuma, S. S. 2019. IMPLEMENTASI SISTEM EKSTERNAL HOTSPOT MENGGUNAKAN OTENTIKASI API SOCIAL MEDIA. Jurnal Mahasiswa Teknik Informatika, 3(1), 306-313.

[2] Wulandoro, A., Fitriyani, F., \& Nurkahfi, G. N. (2016). Desain, Implementasi, Dan Analisis Network Management System (NMS) Berbasis Cacti. eProceedings of Engineering, 3(1).

[3] Styowati, K. D. 2019. PENERAPAN PEMANCAR KONEKSI HOTSPOT MENGGUNAKAN METODE POINT TO MULTI POINT PADA LAYER DATA LINK 


\section{DENGAN PROGRAM MONITORING}

TELEGRAM. Jurnal Mahasiswa Teknik Informatika, 3(1), 152-157.

[4] ANDREGATE, Arsyan. Monitoring Sinyal WLAN Menggunakan InSSIDer. 2017.

[5] Idrus,2016,' Sistem Monitoring Jaringan PT. Exhibition Network Indonesia DenganThe Dude Berbasis Mikrotik', Informatics for educators an professionals, Vol 1, No. $1: 84-93$

[6] Yutanto, H. (2018). Penerapan Model Promosi Berbasis Web Captive Portal Hotspot dengan Manajemen Terpusat. Jurnal Sistem Informasi Bisnis, 8(1), 49-56.

[7] “Pengertian Mikrotik:Fungsi,Fitur,Sejarah \& Jenis-Jenis Mikrotik.”. salamadian.com. 25 Oktober 2019. 27 Maret 2020. https://salamadian.com/pengertian-mikrotik/
[8] Khairina, D. M. (2016). Analisis Keamanan Sistem Login. Informatika Mulawarman: Jurnal Ilmiah Ilmu Komputer, 6(2), 64-67

[9] Iswara, I. B. A. I. (2019). RANCANG BANGUN SISTEM SINGLE IDENTITY INTEGRATION BERBASIS LDAP DI STMIK STIKOM INDONESIA.]

[10] Harjono, E. B. (2017). Analisa Dan Implementasi Dalam Membangun Sistem Operasi Linux Menggunakan Metode LSF Dan REMASTER. SinkrOn, 1(1).

[11] Putra, R. A., \& Sujana, A. P. (2019). Implementasi Cluster Server pada Raspberry Pi dengan Menggunakan Metode Load Balancing. Komputika: Jurnal Sistem Komputer, 8(1), 3743. 